\title{
DISCURSO PARA A CERIMÔNIA DE RECEBIMENTO DO TÍTULO DE PROFESSORA EMÉRITA DA UNB
}

\author{
Maria de Fátima da Silva Verdeaux \\ Universidade de Brasília - UnB
}

\begin{abstract}
Inicio a minha intervenção nessa honrosa e emocionante cerimônia cumprimentando a Magnifica Reitora da Universidade de Brasília, Professora Márcia Abrahão Moura, na figura de quem cumprimento os demais ilustres integrantes da mesa, bem como as autoridades universitárias, os professores, meus familiares, os amigos, os alunos, os ex-alunos e os demais presentes.
\end{abstract}

A atuação como pesquisadora e professora universitária ao longo desses inúmeros anos sempre me proporcionou emoções e surpresas. A que hoje aqui vivo é talvez a maior delas.

Um desejo prevalece: o de agradecer a todos os que participaram da construção deste momento. Em particular e muito especialmente, agradeço pelas gentis palavras do orador desta cerimônia, meu colega do Instituto de Física da UnB e ex orientando o Professor Marcello Ferreira. Mesmo sabendo que elas são inspiradas por sua bondade e cortesia, não me furto a confessar que gostei muito de ouvi-las e que gostaria ainda mais de merecê-las. Agradeço ao Professor Ademir Eugênio de Santana que iniciou todo o processo para a outorga do título e infelizmente hoje não pode estar aqui presente.

Também agradeço aos membros da minha comitiva: meu pai, Gercino Alves da Silva, pilar estruturante da minha vida; meu esposo, companheiro e incentivador, o compositor e pianista talentoso Cyrille Verdeaux; e meus colegas que aceitaram muito gentilmente o convite para estar hoje aqui comigo: os professores Adriana Pereira Ibaldo, José Felippe Beaklini Filho, Marcello Ferreira e Olavo Leopoldino da Silva.

Meus sinceros agradecimentos aos colegas do Instituto de Física e aos membros do Consuni que indicaram e me concederam um título tão importante: Professora Emérita. Ressalto que essa honraria tem um significado suplementar para mim, pois sou a primeira mulher do IF a recebê-la. Isso se reveste de simbologia em uma área do conhecimento a Física e em uma carreira essa a de pesquisadora ainda tão masculinas, além de brancas, eurocêntricas e elitizadas.

Colegas professores, alunos, ex-alunos e todos os amigos e amigas que me honram com a sua presença, meu muito obrigada.

Nao os aborrecerei com meu curriculo, mas pontuarei alguns fatos e alguns aspectos que acredito terem trazido-me ate aqui. Comeco falando sobre minha origem e formacao. 
Nasci em uma casa de taipas em São Joaquim do Monte a 50 quilômetros de Caruaru, em Pernambuco. Meu pai, vendo a família aumentar e sem ter condições de educar adequadamente os filhos, partiu em um pau-de-arara, deixando minha mãe grávida de meu irmão e eu ainda com um ano de idade. O objetivo era ser candango em Brasília; porém, passando por Minas Gerais, ele mudou de ideia e decidiu seguir para São Paulo. Meu irmão nasceu no dia da inauguração de Brasília, vivendo infelizmente apenas 19 dias. Assim que meu pai se estabeleceu em Santo André, na região do ABC Paulista, enviou dinheiro para que minha mãe e eu pudéssemos ir reencontrá-lo. Então, foi assim que fomos para Santo André, onde cresci e fiz todos meus estudos fundamentais em escolas públicas e onde até hoje meu pai reside.

Algumas décadas depois de quase ter virado candanga, o Professor Paulo César de Morais, em passagem por Paris onde eu realizava meu pós doutorado, convidou-me a fazer o concurso para uma vaga em seu grupo de pesquisa na UnB. Em 1997, vi-me novamente em face do meu destino de ser candanga. Ali começava a minha vida na UnB.

É difícil separar a vida em Brasília do amor por meu marido. Cyrille Verdeaux entrou em minha vida em 2002, e através de seus olhos de artista aprendi a amar, defender e respeitar Brasília. Aqui me encantei pela cidade, por seus habitantes com quem convivi e, sobretudo, pelos ipês que tanto fotografei.

Em minha atuação na UnB, como não podia ser diferente, dado o meu amor pelo ensino, eu sempre dei aulas na licenciatura da Física. Essa sempre me foi uma grande realização. Hoje, posso dizer que praticamente $80 \%$ dos professores de Física do DF foram alunos meus ou na graduação, ou na pós-graduação em Ensino.

Um dos marcos e da centralidade dessa atuação tem origem em novembro de 2012, quando a Professora Eliana dos Reis Nunes, amiga desde minha chegada aqui na UnB, também ligada ao Ensino de Física, propôs-me que apresentássemos a candidatura do IF para ser uma das instituições ofertantes do Mestrado Nacional Profissional em Ensino de Física o MNPEF, uma pós-graduação em rede que à época estava sendo criada pela Sociedade Brasileira de Física. Do grupo de Ensino de Física, apenas ela e eu apoiávamos essa iniciativa. Após reuniões e alinhamentos de perspectivas, juntamente com alguns professores do então Centro Internacional de Física da Matéria Condensada (hoje, apenas Centro Internacional de Física), decidimos apresentarmos juntos a proposta de oferta desse curso de pós-graduação. Como professora da licenciatura, além de pesquisadora da área de ensino de Física, eu não podia me furtar da responsabilidade de capacitar, em nível de mestrado e em uma proposta consistente e inovadora, professores da Educação Básica, relativamente ao domínio da Física e de técnicas atuais de ensino para a aplicação em sala de aula.

A proposta que apresentamos à Sociedade Brasileira de Física foi aprovada e os colegas escolheram-me como coordenadora e o Professor Joaquim José Soares Neto, como vicecoordenador do curso. Em agosto de 2014, tiveram início as aulas da primeira turma do Polo 01-UnB do MNPEF.

Para a implementação do programa do curso, trabalhamos com orçamento zero e sem nenhum apoio técnico-administrativo, tendo o apoio apenas do IF, na figura do então diretor, Professor José Felippe Beaklini Filho, e do então Centro Internacional de Física da Matéria Condensada, à época dirigido pelo Professor Tarciso Marciano da Rocha Filho, que nos 
disponibilizou a estrutura física para uma secretaria, além das salas de aulas e equipamentos necessários.

A UnB deu seu apoio apenas com a assinatura do Decano na proposta, mas nem na página do Decanato de Pós-Graduação aparecíamos como um curso de mestrado. Aprendi que na vida universitária tudo é produto de muitas lutas, de muita persistência. Nesse caso, foi junto com o Professor José Mauro Barbosa Ribeiro do Instituto de Artes da UnB que batalhei para que os nossos mestrados profissionais, ambos em rede, fossem reconhecidos pela UnB como cursos regulares, bem como que nós próprios fôssemos reconhecidos institucionalmente como coordenadores de pós-graduação. Foi penoso, mas exitoso: conseguimos que os cursos profissionais em rede, que prestam um imenso trabalho social, tivessem o mesmo status dos programas acadêmicos. Toda luta, entretanto, nos leva a vitórias parciais e circunstanciais: obtivemos o reconhecimento como curso de pósgraduação, mas ainda resta reconhecer um conjunto de necessidades e mesmo direitos de cursos dessa natureza, especialmente o de dispor de recursos financeiros, apoio de pessoal e direitos estudantis. São lutas que ficam aos que me sucederam, mas que permanecem em meu horizonte como consciência crítica e dever de ação política.

Ainda no âmbito do MNPEF, em 2016, fui convidada, em nome da Sociedade Brasileira de Física, pelos professores Marco Antônio Moreira e Nelson Studart, ilustres pesquisadores da área, a fazer parte da Comissão Nacional de Pós-Graduação do MNPEF. Foi então que começaram as viagens pelo Brasil, para visitar as demais instituições da rede, e quando tive o privilégio de compreender a importância e ver o alcance social dessa iniciativa. Vivenciei a realidade do Brasil de uma forma muito crua. Posso citar fatos como os de professores-mestrandos do programa que levavam doze horas de barco para chegarem até a universidade. Isso, claro, no sentido da correnteza dos rios Amazonas ou Tapajós, pois no sentido contrário o tempo chegava a quatorze horas. Esses mesmo professores retornavam às suas escolas de atuação para ministrarem suas aulas à sombra de árvores, para alunos que só podiam apoiar os cadernos sobre as pernas, por falta de classes. Este é apenas um de muitos outros exemplos de quão longe esse programa social acessa. Seria curioso, se já não fosse lamentável, que há um conjunto de professores universitários que, dentro de suas limitações e até mesmo de suas despreocupações sociais, ousam a tecer críticas não construtivas em relação a essa pós-graduação, baseando-se em argumentos que não expressam, absolutamente, a natureza, o formato e a função social dessa ação.

O professor Marcello Ferreira, vice-coordenador do MNPEF na UnB, é atualmente o representante dos coordenadores de polos na Comissão Nacional de Pós-Graduação. Como um bom ex-orientando, ele me suplantou e hoje é também o vice-coordenador nacional do Programa junto à Sociedade Brasileira de Física. Isso reforça o protagonismo da UnB na constituição e na consolidação desse curso.

Outro ponto que quero ressaltar é a importância da Educação a Distância e a participação do IF, que oferta sua licenciatura em Física EaD sob a competente coordenação do professor Olavo Leopoldino da Silva Filho. Essa é outra distinta ação, de grandiosa relevância social, que, como o MNPEF, recebe duras e infundamentadas críticas. Seu sucesso, no entanto, é incontestável, tanto pelo valor que agrega à formação de centenas de jovens que não teriam acesso à formação superior pública e de qualidade, quanto pelos números de inscritos no vestibular deste ano, que se aproximaram de três mil. Não consigo aceitar que as críticas 
sejam feitas apenas com o argumento de ah, eu não gosto de EaD, ou ah, o MNPEF é conteudista. Eu penso que é dever de todo intelectual honesto buscar enxergar além de nossas próprias necessidades e pensar de forma mais humana e empática, para que mais e mais pessoas tenham a mesma oportunidade, que nós próprios tivemos, de realizar nossos estudos e nossos sonhos.

Também quero ressaltar a importância do trabalho realizado, no âmbito do Instituto de Física, pela professora Adriana Pereira Ibaldo, com os seus projetos Atraindo meninas e jovens mulheres do DF para a carreira em Física . Espero que com essas ações tenhamos, cada vez mais, muitas meninas no IF; muitas professoras e pesquisadoras de sucesso na área de Física.

Ao IF, gostaria de deixar uma sugestão, para que em sua página de Web sejam inseridos marcos de sua rica história. Seria de grande relevância que, na página da internet, haja um link com o nome e as principais contribuições dos professores que dedicaram suas vidas durante décadas ao IF, mas que, hoje aposentados, não figuram em lugar algum. Essas importantes contribuições, junto com suas aposentadorias, parecem simplesmente deixar de existir e seus feitos esvanecem no ar, permanecendo apenas na lembrança daqueles que com eles conviveram.

Já me encaminhando para as palavras finais, preciso destacar que as dificuldades que o País atravessa neste momento fazem com que este e outros centros de ensino e pesquisa que têm consciência de sua qualidade e de seu papel no desenvolvimento e na autonomia da Nação evitem, a todo o custo, ceder à pressão dessas dificuldades que têm a particular malícia de destruir mais e mais depressa o que é melhor. O período atual é de definições claras e posições firmes para preservar o que temos de bom. Foi com base nisso que busquei pautar a minha carreira profissional e a minha atuação política, em parte a que atribuo este inesquecível momento.

Cabe à universidade, e particularmente à universidade pública, a obrigação de avaliar e dar contas à sociedade do seu desempenho nas atividades essenciais de desenvolver a ciência, a arte e a cultura; de atender à demanda social por educação superior; e de formar profissionais competentes, atualizados e diversificados. Isso tudo, é claro, sem perder o bom humor, a criatividade e a solidariedade.

A mensagem que gostaria de deixar, como emérita, é aquela que procurei praticar em minha vida pessoal e acadêmica: excelência sempre, respeito à diversidade e firmeza nos propósitos e ações. Magnífica Reitora, ao encerrar estas palavras, gostaria, mais uma vez, de agradecer a Vossa Magnificência e ao Conselho Universitário pela generosidade de me outorgar este honroso título.

Meu agradecimento maior é aos estudantes que tive, aos quais tributo o estímulo para perseverar durante décadas no ensino e na pesquisa.

Muito obrigada!

Brasília-DF, 6 de dezembro de 2019. 